


\section{behavioral sciences}

an Open Access Journal by MDPI

Editor-in-Chief

Prof. Dr. Gianluca Serafini

\begin{abstract}
Message from the Editor-in-Chief
With warm greetings, it is a pleasure to invite you to contribute a research article or comprehensive review for consideration and publication in Behavioral Sciences (ISSN 2076-328X). Behavioral Sciences is an international, scientific, open access journal providing an advanced forum for discussions and research regarding the intersection between psychiatry, neuroscience, psychology, cognitive and behavioral sciences, and behavioral biology. More information are available at: https://www.mdpi.com/ journal/behavsci. We would be pleased to welcome you as one of our authors and have the opportunity to consider your work for publication.
\end{abstract}

\section{Author Benefits}

Open Access Unlimited and free access for readers

C No Copyright Constraints Retain copyright of your work and free use of your article

\section{$\&$ Thorough Peer-Review}

【] No Space Constraints, No Extra Space or Color Charges No restriction on the length of the papers, number of figures or colors

Journal Rank CiteScore-Q1 (Development)

Coverage by Leading Indexing Services Scopus, SSCI (Web of Science), PubMed, PMC, and many other databases 


\section{Aims and Scope}

Behavioral Sciences (ISSN 2076-328X) is a peer-reviewed journal that publishes original articles, critical and systematic reviews, research notes and short communications in the area of psychiatry, neuroscience, psychology, cognitive and behavioral sciences, and behavioral biology. Our aim is to encourage scientists to publish their experimental and theoretical results in as much detail as possible. There is no restriction on the length of the papers. The full experimental details of each reserach paper need to be provided so that the results can be reproduced. Electronic files or soware regarding the full details of the calculation and experimental procedure, if unable to be published in a normal way, can be deposited as supplementary material.

\section{Scope:}

Psychiatry
Psychology
Psychobiology
Experimental and clinical neurosciences
Behavior genetics
Social neuroscience
Neurocognitive sciences
Sociology and social networks
Applied anthropology
Management science
Operations research
Organizational behavior

\section{Editorial Office}

Behavioral Sciences Editorial Office behavsci@mdpi.com MDPI, St. Alban-Anlage 66 4052 Basel, Switzerland Tel: +41616837734 www.mdpi.com mdpi.com/journal/behavsci 


\section{MDPI is a member of}

\section{CASPA}

The Association of Learned \& Profession

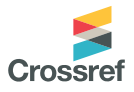

\section{STM}

Society

for Scholarly

Publishing
$|\mathbf{C}| \mathbf{O}|\mathbf{P}| \mathbf{E}$

SPARC*

Europe

\section{DOAJ}

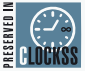

ORCID

\section{Follow Us}

f facebook.com/MDPIOpenAccessPublishing

3.twitter.com/MDPIOpenAccess

in linkedin.com/company/mdpi

$\mathbf{6}^{\text {") }}$ weibo.com/mdpicn

Wechat:MDPI-China

(1) blog.mdpi.com

See www.mdpi.com for a full list of offices and contact information. MDPI is a company registered in Basel, Switzerland, No. CH-270.3.014.334-3, whose registered office is at St. Alban-Anlage 66, CH-4052 Basel, Switzerland. 